Note: This is a pre-copy-editing, author-produced PDF of an article accepted for publication in Substance Use \& Misuse following peer review. The definitive publisher-authenticated version [Comiskey C (2001) Methods for estimating prevalence of opiate use as an aid to policy and planning,, Substance Use \& Misuse, 36(1-2):131-50] is available online at http://www. informaworld.com/smpp/content $\sim \mathrm{db}=\mathrm{all} \sim$ content $=\mathrm{a} 713733461$

\title{
METHODS FOR ESTIMATING PREVALENCE OF OPIATE USE AS AN AID TO POLICY AND PLANNING
}

\author{
Catherine M. Comiskey, B.A., M.Sc., Ph.D. \\ Department of Mathematics, National University of Ireland, Maynooth, Co. Kildare, \\ Ireland
}

\begin{abstract}
Public health planning continues to be troubled by the uncertainty of the extent of hidden drug use. Methods for estimating the prevalence of opiate use are discussed. These include multisource enumeration, death multiplier, multiple indicator, and capture-recapture methods. The feasibility and data requirements for each of these methods is illustrated for the first time in an Irish context. Estimates presented are the result of years of intensive collaboration between previously unconnected government, health, and legal agencies. Finally, the implications of the methods and their results for the planning and provision of medical and social policy are highlighted and discussed.
\end{abstract}

Key Words: Opiate use; Prevalence estimation; Policy; Ireland.

For conscientious policy makers dealing with drug problems at (he national and local levels, prevalence estimation ought to be a fundamental element of sensible decision making (1).

\section{INTRODUCTION}

Interest in developing and implementing methods for estimating drug use prevalence and related medical, social, and economic problems is expanding on both a European and global level. Evidence for this phenomenon can be seen in the recent emergence of multidisciplinary international networks of researchers and related publications on local, national, and global drug use prevalence and implications (2-6). This phenomenon, however, pre-empts the questions of what prevalence is, why this predilection with its estimation, and what reliable methods are available and universally applicable for its estimation. In this paper the rationale behind prevalence estimation is defined and explained and the generally applicable methods for its estimation are critically evaluated. These are then illustrated for the first time in an Irish context and finally the wider implications of prevalence results for policy planning are discussed.

Please use the following citation: Comiskey C (2001) Methods for estimating prevalence of opiate use as an aid to policy and planning, (Author postprint) in Substance Use \& Misuse, 36(1-2):131-50 [Accessed: (date) from www.drugsandalcohol.ie] 
According to Hay (7), the prevalence of a certain social attribute is defined as the proportion of people possessing that attribute. This may be expressed as a percentage or as a rate. This may be expressed as a certain number per hundred, per thousand, or per hundred thousand of the total population. Sometimes the actual number of individuals is used instead of the prevalence. Without previous knowledge of the size of the total population, use of the actual number possessing the attribute can be misleading. A recent study of opiate use in five European cities showed that the number of opiate users in Rome in 1996 was similar to the number of opiate users in Dublin in the same year. This may lead one to assume that the size of the problem in the two cities was of a similar scale. However, on closer examination of the prevalence rates it was seen that the prevalence rate in Dublin was approximately twice that of Rome (8). In addition, it is important to stress that the concept of prevalence also requires some indication of the time period that is being examined. Drug use and means of taking drugs can be transient activities and are subject to availability and fashion. In addition, drug use should also take into consideration a drug's action, that is short-term as in cocaine and crack or long-term action as with psychedelics such as LSD, where time perspective is also badly affected.

Clearly in an area as highly politicized as drug use, budgetary decisions, elections, and political will are of importance. When one estimates prevalence of opiate use it is also important to define what is being estimated, why it is being estimated, and when is it to be estimated. What is to be counted and what is the case definition? In some studies the definition of a case may refer to heroin dependence or heroin addiction. In others the case may be an intravenous heroin user or may even be a prescribed methadone user. Hartnoll discusses this issue in a multi-centered European context. He states that the answer to the question of what is being measured is closely linked to the purpose and why a prevalence estimate is sought. If the purpose of an opiate prevalence estimate is to assess possible treatment needs, then the definition should relate to potential clients or future clients. If it is to assess demand and the extent of the illicit market then all opiate users should be included regardless of their likelihood of seeking treatment (9).

Finally once the rationale for a prevalence study is decided, the case defined, and numbers estimated, it is imperative that such studies are not viewed as a final or endpoint, but, rather as a first step in a dynamic and progressive process. Further information and interdisciplinary collaboration between an academic and politician is necessary for the provision of relevant action, policy development, and service planning. Unfortunately, it is often the case that policy decision makers in this area are not influenced by available research. Likewise, researchers continue to remain in the academic realm with little regard to application and the notion of the "Transfer of Technology" remains an ideal.

\section{METHODS FOR ESTIMATING PREVALENCE AND THEIR DATA REQUIREMENTS}

\section{General Population Surveys}

One of the traditional and most familiar methods used to estimate prevalence of drug use in a population is a survey based on random sampling of the population concerned. This method has been widely used within localities (10) and countries (11). When an inter-country comparison is required this method proves costly to administer and difficult to ensure comparability of case definition. The exception to this is when a specific subgroup of the population is targeted. A recent illustration of the advantages and limitations of such a project is the European School Survey Project on Alcohol and Other Drugs, a survey of substance abuse among school-aged children (12). A summary of results on lifetime prevalence of any illicit drug is provided in Table 1. Despite the

Please use the following citation: Comiskey C (2001) Methods for estimating prevalence of opiate use as an aid to policy and planning, (Author postprint) in Substance Use \& Misuse, 36(1-2):131-50 [Accessed: (date) from www.drugsandalcohol.ie] 
relative success of the ESPAD study, there are some types of drug use that often cannot be assessed reliably by this method. These would include the rarer or stigmatized problematic patterns of drug use such as intravenous drug use or illegal opiate use. As a result, alternative methods are needed to complement the information obtained in such population surveys.

\section{Case Finding: Multisource Enumeration}

Another obvious and popular method for estimating opiate use is the multisource enumeration or intensive case finding method (13). This method may be of value in provincial towns where the numbers of addicts are small. Even within this context the method has its drawbacks. In a smaller town one may have the advantage of having access to all the different sources of data on opiate cases but to avoid over-counting, it is necessary to identify overlaps within and between the data sources. This may lead to the disclosure of confidential information on an individual case, in addition, the researcher is still presented with the problem of the hidden opiate drug user. It is widely accepted that case notifications under-represent the total opioid-using population. When the number of hidden users is missed or unknown this can have serious implications for the planning and financial provision of the necessary treatment services. For example, education and awareness campaigns may be targeted at the gender and age group in treatment and may miss the hidden group that may be of a different age or gender or even geographical location within a city or region. An example of a multisource enumeration study is provided in the Results section.

Table 1. Lifetime Experience of Any Illicit Drug (Percentages Among All Students)

\begin{tabular}{ll}
\hline United Kingdom & 42 \\
United States & 41 \\
Ireland & 37 \\
Czech Republic & 23 \\
Italy & 21 \\
Denmark & 18 \\
Ukraine & 14 \\
Slovenia & 13 \\
Faroe Island & 12 \\
Iceland & 10 \\
Slovak Republic & 10 \\
Poland & 9 \\
Croatia & 8 \\
Estonia & 8 \\
Portugal & 8 \\
Cyprus & 6 \\
Norway & 6 \\
Sweden & 6 \\
Finland & 5 \\
Hungary & 5 \\
Istanbul & 5 \\
Lithuania & 3 \\
Malta & 2 \\
\hline
\end{tabular}

Please use the following citation: Comiskey C (2001) Methods for estimating prevalence of opiate use as an aid to policy and planning, (Author postprint) in Substance Use \& Misuse, 36(1-2):131-50 [Accessed: (date) from www.drugsandalcohol.ie] 


\section{Death Multiplier Method}

As the case finding method is not realistic in a large metropolitan area or for a country as a whole, more indirect and cheaper methods for estimating prevalence have been developed. These methods do, however, make assumptions about the relation of observable events to the whole. One such method is the death multiplier method that was used in the United States during the 1970s (14). This method assumes a constant linear relation between prevalence of use and the number of deaths. It is with this seemingly simple assumption that the weakness of this method lies. With the advances made in dynamic modeling and chaos and the application of these modeling techniques to complex social and medical phenomena we are increasingly aware of the dangers of oversimplifying the models used to estimate prevalence. For example, in estimating the spread and incidence of the human immunodeficiency virus among intravenenous drug users, Comiskey (15) and Comiskey and Ruskin (16) use complex nonlinear models of the transmission dynamics of the disease. Substance use is also a complex phenomenon and many other factors, for example, mode of administration of the opiate used, may also influence the linearity assumption. It is widely accepted that mortality rates for those who smoke or sniff opiate are lower than mortality rates for those who inject. Changes in the purity of the opium used may also affect the user's mortality rate, In addition, government policy and procedures on death notifications may delay or distort the number of opiate-related deaths. As a result of these limitations it is possible for the method to underestimate the true prevalence. The death multiplier method, however, has been used extensively from studies in London (13) to studies in Germany (17) and Rome (18). We illustrate the first application of the method to the city of Dublin from 1990 to 1996 in the Results section.

\section{The Multivariate Indicator Method}

A simple yet comprehensive description of this method is provided by Mariani (19). The author states that the application of this method requires a breakdown of national states by regions or provinces and data indicating the prevalence of drug use. These data must be available for each of these regions. For at least two regions, reliable prevalence estimates derived independently are also required. Here, the method is described step by step and follows the application of the method as described for Italy (20). Data indicating the prevalence of drug use must be collected for a 1-year period for each region. The following variables may be selected as indicators:

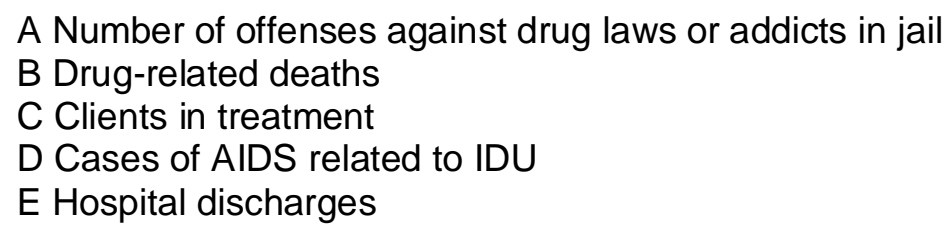

In addition, the population size $F$ of the population at risk is needed. In (19) the population at risk was defined as the 15- to 54-year-olds in 1995. As already mentioned, for at least two regions reliable estimates $G$ (maybe resulting from a cap tore-recapture study) are necessary. These regions are called anchor points. $G$ (for each of the variables $A$ to $E$ ) and the figure per 100,000 inhabitants for each region have to be calculated.

Please use the following citation: Comiskey C (2001) Methods for estimating prevalence of opiate use as an aid to policy and planning, (Author postprint) in Substance Use \& Misuse, 36(1-2):131-50 [Accessed: (date) from www.drugsandalcohol.ie] 


$$
\begin{aligned}
& A \_F=A \times 100,000 / F \\
& G, F=G \times 100,000 / F
\end{aligned}
$$

Principal components analysis requires standardized values for $\mathrm{A}-\mathrm{F}$ to $\mathrm{C}-\mathrm{F}$ (subtracting the mean and dividing by the standard deviate). For this analysis two factors are extracted and rotated, and the coefficients of the first one are saved. A linear regression (dependent variable: $G-F$, independent variable: coefficients of the first factor) results in estimated prevalence rates per 100,000 inhabitants. Finally, these have to be transformed to prevalence estimates for the regions (multiplying with $\mathrm{F}$ and dividing by 100,000). This method assumes a linear relationship between the unobserved prevalence and the observed indicators. This assumption has however been criticized (21). In the Results section the limitations of the method are illustrated for the first time with data from Dublin, Ireland, in 1996.

\section{Capture-Recapture Method}

The capture-recapture method is an indirect method that generates a prevalence estimate based on the degree of overlap between two or more separate samples of the population under study. For example, when working with three samples or data sets, the first sample provides the individuals for marking or tagging and is returned to the population. The second and third sample provides the recaptures. Using the number of individuals caught in two or three samples and the numbers caught in one sample, it is possible to estimate the number not caught in any of the three samples, thus providing an estimate of the total population size. In addition, the method allows the confidence intervals of the population estimate to be calculated. It was originally used in ecological studies to assess the size of animal populations and in human populations to ascertain completion of census data. In epidemiology, different registers of the disease have been used as "capture" samples, with names or confidential identifiers used to tag unique individuals to assess the overlap between samples. The assumptions of the model are as follows:

1. There is no change to the population during the investigation.

2. There is no loss of tags; individuals can be matched from capture to recapture.

3. For each sample, each individual has the same chance of being included in the sample.

4. If using only two samples then the samples are independent.

To implement the method we arrange the data from the three samples in a $2^{3}$ table

\begin{tabular}{|c|c|c|c|c|}
\hline $\begin{array}{l}\text { First } \\
\text { Sample }\end{array}$ & $\begin{array}{l}\text { Second Sample } \\
\text { Present, Third } \\
\text { Sample Present }\end{array}$ & $\begin{array}{l}\text { Second Sample } \\
\text { Absent, Third } \\
\text { Sample Present }\end{array}$ & $\begin{array}{l}\text { Second Sample } \\
\text { Present, Third } \\
\text { Sample Absent }\end{array}$ & $\begin{array}{l}\text { Second Sample } \\
\text { Absent, Third } \\
\text { Sample Absent }\end{array}$ \\
\hline Present & $\mathrm{X}_{111}$ & $\mathrm{X}_{121}$ & $\mathrm{X}_{112}$ & $x_{122}$ \\
\hline Absent & $X_{121}$ & $x_{221}$ & $\mathrm{X}_{212}$ & - \\
\hline
\end{tabular}
with one missing cell:

Let $\mathrm{n}=\mathrm{x}_{111}+\mathrm{x}_{121}+\mathrm{x}_{211}+\mathrm{x}_{221}+\mathrm{x}_{112}+\mathrm{x}_{122}+\mathrm{x}_{212}$. In addition, let $\mathrm{m}_{\mathrm{ijk}}$ be the expected value for the number of individuals in the (ijk) cell. Let $\mathrm{p}_{\mathrm{ijk}}$ be the underlying probability

Please use the following citation: Comiskey C (2001) Methods for estimating prevalence of opiate use as an aid to policy and planning, (Author postprint) in Substance Use \& Misuse, 36(1-2):131-50 [Accessed: (date) from www.drugsandalcohol.ie] 
corresponding to the (ijk) cell. For example, $\mathrm{p}_{111}$ is the probability of being in all samples. The probability of being in none of the samples is $P_{222}$ and we assume $p_{222}>0$.We have $m_{i j k}=p_{i j k}\left(n / 1-p_{222}\right) f o r(i, j, k)=(2,2,2)$. The loglinear models available for our use and their interpretations are as follows:

1. The three samples are independent:

$\log m_{\mathrm{ijk}}=u+u_{1(i)}+u_{2(j)}+u_{3(k)}$

2. The third sample is independent of the first two:

$\log m_{i \mathrm{jk}}=u+u_{1(\mathrm{i})}+u_{2(\mathrm{j})}+u_{3(\mathrm{k})}+u_{12(\mathrm{ij})}$

(there are three versions of this model).

3. Two pairs of samples are related:

$\log m_{i j k}=u+u_{1(i)},+u_{2(j)}+u_{3(k)}+u_{12(i j)+} u_{23(j k)}$

(there are also three versions of this model).

4. All pairwise relationships are present:

$\log m_{i j k}=u+u_{1(i)},+u_{2(j)}+u_{3(k)}+u 1_{2(j)}+u_{23(j k)+} u_{13(j k)}$

The model chosen can then be used to estimate the contents of the missing cell and confidence limits of the total estimated population, using formulae that take account of specified dependencies. A detailed description of the method and its applications has been provided elsewhere (22-24).

Use of this method for estimating the prevalence of drug misuse has been applied in diverse communities throughout the world, for example, in The Netherlands (25), Australia (26), Italy (27), Asia (28), and Europe (29).

\section{RESULTS}

\section{Applying Multisource Enumeration Techniques}

Three main sources of information on drug users living in Dublin were used. The Central Methadone Treatment List, the Hospital Inpatient Enquiry database (known as HIPE), and the database for arrests in 1996. Before, the collation of the data approval from the Assistant Data Protection Commissioner was sought and gained. Dublin is the capital city of the Republic of Ireland. The 1996 census of the Total population of Ireland identified 3,626,087 inhabitants. This represented a $2.8 \%$ increase from the previous census in 1991. The population of Dublin city and county was $1,058,714$. This represents over $29 \%$ of the total population. In addition, of those living in Dublin 430,385

Please use the following citation: Comiskey C (2001) Methods for estimating prevalence of opiate use as an aid to policy and planning, (Author postprint) in Substance Use \& Misuse, 36(1-2):131-50 [Accessed: (date) from www.drugsandalcohol.ie] 
(or $41 \%$ ) are under the age of 25 years and 635,329 are between the ages of 15 and 54 . This demographic profile is in sharp contrast to other European cities where the populations are considerably older. A detailed age profile of the Dublin population is provided in Table 2.

The Central Methadone Treatment List is maintained jointly by the Eastern Health Board and the Drug Treatment Centre. It was set up in 1994 and it records those who have ever, since 1994, received methadone from either the Eastern Health Board, the Drug User Treatment Centre, or a general practitioner (GP). At present, the central list is a combination of notifications from approximately 15 treatment centres and 75 individual GPs. Notification of cases by GPs is voluntary and, as a result, not all patients being prescribed methadone are included in the list. The list therefore represents an underestimate of the numbers of those in receipt of methadone treatment. From the list, initials, date of birth, and sex of those on methadone in 1996 were provided. We found that 3170 individuals were in receipt of methadone in Dublin in 1996. The number on the list at any one time point in 1996 would differ from this as some individuals may be on a long-term maintenance program while others may be on a short detoxification program. The mean age of those receiving methadone in 1996 was found to be 27.24 years, with a standard deviation of 6.87 years. There were $2225(70.2 \%)$ males and $920(29.0 \%)$ females, and for $25(0.8 \%)$ clients the sex was unknown.

Table 2.

\begin{tabular}{lllllll}
\hline & \multicolumn{5}{c}{ Age (years) } \\
& $0-14$ & $15-24$ & $25-34$ & $35-44$ & $45-54$ & $>54$ \\
\hline Male & 120,444 & 97,222 & 84,350 & 69,540 & 56,682 & 81,178 \\
Female & 112,700 & 100,009 & 91,891 & 75,188 & 60,447 & 109,063 \\
Total & 233,144 & 197,231 & 176,241 & 144,728 & 117,129 & 190,241 \\
\hline
\end{tabular}

Source: Census 1996. Principal Demographic Results. Central Statistics Office.

The Economic and Social Research Institute, Dublin, maintains the central HIPE database. This database records all discharges from Irish hospitals and the primary and secondary diagnoses of those patients discharged. Those patients who used opiate were identified from the ICD-9 classification code 304.0, opioid type dependence, code 304.7, combinations of opioid type drug with any other, and code 305.5, opioid abuse. As of March 1997 the central HIPE database identified 603 patients in the Dublin area with these codes as a primary or secondary diagnosis. These 603 patients were identified in 12 different Dublin hospitals. However, 92\% of these cases were in four of the Dublin hospitals. As the central 'HIPE database does not have access to patients' initials it was decided to contact these four hospitals individually and seek their permission for access to this data. Permission was granted and initials, date of birth, sex, and postal code of 545 opiate drug users were obtained. The four hospitals involved in the study were St. James Hospital, Beaumont Hospital, the Mater Misericordiae Hospital, and the Meath and Adelaide Hospital combined. The variables recorded were surname, initial, sex, date of birth, and Dublin postal code. Of the 545 patients identified, $353(64.77 \%)$ were male and $192(35.23 \%)$ were female.

In 1996 the assistant police commissioner conducted a study on illicit drug use and related criminal activity in the Dublin metropolitan area (30). After an extensive search of all police records held at police station level, a database consisting of 4105 individuals identified with drug use was constructed from records held in 17 different police districts across the city. The majority of these were male, unemployed, and living at home. Males

Please use the following citation: Comiskey C (2001) Methods for estimating prevalence of opiate use as an aid to policy and planning, (Author postprint) in Substance Use \& Misuse, 36(1-2):131-50 [Accessed: (date) from www.drugsandalcohol.ie] 
accounted for 3467 (84.46\%) of cases and females accounted for $638(15.54 \%)$ of cases. Four out of five (80\%) were in the 15- to 30 -year-old age group, with the youngest user being 12 years and the eldest being 60 years. The principal drugs used were opiates (heroin and methadone) with 3817 (93\%) users identified.

From the three central and diverse data sources described above, unique individuals were identified within and between each of the data sources using initials, date of birth, sex, and postal code. To make comparisons with other European studies, numbers of opiate users lying between the ages of 15 and 54 years were recorded and prevalence rates for these age groups were computed using the 1996 Census of Ireland report. Details of results are provided in Table 3.

\section{Application of the Death Multiplier Method}

Table 3. Multisource Enumeration of Prevalence of Opiate Use in Dublin in 1996

\begin{tabular}{|c|c|c|c|c|c|c|c|}
\hline & \multicolumn{3}{|c|}{ Male } & \multicolumn{3}{|c|}{ Female } & \multirow{2}{*}{$\begin{array}{l}\text { Total } \\
(15-54 \\
\text { (yrs)] }\end{array}$} \\
\hline & $\begin{array}{l}15-24 \\
(\mathrm{yrs})\end{array}$ & $\begin{array}{l}25-34 \\
(\mathrm{yrs})\end{array}$ & $\begin{array}{l}35-54 \\
\text { (yrs) }\end{array}$ & $\begin{array}{l}15-24 \\
(\mathrm{yrs})\end{array}$ & $\begin{array}{l}25-34 \\
\text { (yrs) }\end{array}$ & $\begin{array}{l}35-54 \\
(y r s)\end{array}$ & \\
\hline Source 1: Methadone list & 925 & 986 & 338 & 450 & 375 & 95 & 3169 \\
\hline Source 2: HIPE database & 133 & 165 & 55 & 99 & 73 & 20 & 545 \\
\hline Source 3: Police arrests & 1820 & 1164 & 218 & 371 & 179 & 35 & 3787 \\
\hline Total contacts & 2878 & 2315 & 611 & 920 & 627 & 150 & 7501 \\
\hline Individuals identified & 2469 & 1874 & 534 & 755 & 506 & 126 & 6264 \\
\hline $\begin{array}{l}\text { Prevalence per } 1000 \text { of } \\
\text { population }\end{array}$ & 25 & 22 & 4 & 8 & 6 & 1 & 10 \\
\hline
\end{tabular}

A multiplier rate of 200 , based on a mortality rate of $0.5 \%$ derived from a New York study of heroin injectors, was used to estimate the number of drug injectors in the District of Columbia (DC) (14). Having applied the New York mortality rate of $0.5 \%$ to the 75 heroin-related deaths to obtain a figure of 15,000 , the number of known heroin addicts receiving treatment was added to arrive at a figure of 17,700 . This compared favorably to two sample capture-recapture estimates of 19,900 and 20,400 that provided a cross validation to the death multiplier method.

A study of the number of opiate dependers in parts of London also used the method (13). The number of deaths in the study was obtained from a comprehensive search of coroners' records. The authors based their multiplier on previous UK studies that found death rates of $1-2 \%$ among those attending clinics for opiate use. In Germany mortality rates ranging from $0.65 \%$ to $3.96 \%$ were applied to opiate related deaths from 1976 to 1995 (17).

In 1996, government ministerial permission for access to data on opiate-related deaths in Dublin was sought and granted through the office of the General Registrar of Births, Deaths, and Marriages. The Central Statistics Office, which maintains this database, subsequently provided a table summarizing deaths in Dublin for ICD-9 cause of death code 304.0 (opioid type dependence) between 1990 and 1996. During that time period no deaths were assigned a code of 304.7 or 305.5. In the report from the Central Statistics Office it was stated that data after 1994 may change as outstanding returns come in and as such the data provided below are subject to considerable reporting delays and can be considered an underestimate of the true number of opiate related deaths. In addition, it is known that in Dublin the primary route of administration of opiates is changing from injecting to smoking and as such mortality rates would be

Please use the following citation: Comiskey C (2001) Methods for estimating prevalence of opiate use as an aid to policy and planning, (Author postprint) in Substance Use \& Misuse, 36(1-2):131-50 [Accessed: (date) from www.drugsandalcohol.ie] 
decreasing. For both of these reasons, the Dupont and Piemme (14) approach with a mortality rate of $0.5 \%$ was implemented. Table 4 provides the results of this analysis.

Table 4. Prevalence of Opiate use in Dublin from 1990 to 1996 Using the Death Multiplier Method

\begin{tabular}{|c|c|c|c|c|}
\hline Year & $\begin{array}{l}\text { Number of } \\
\text { Deaths }\end{array}$ & $\begin{array}{l}\text { Estimate with } 0.5 \% \\
\text { Mortality Rate }\end{array}$ & $\begin{array}{l}\text { Numbers in } \\
\text { Treatment }^{\text {a }}\end{array}$ & $\begin{array}{l}\text { Prevalence Estimate with } 0.5 \% \\
\text { Mortality Rate + Numbers in Treatment }\end{array}$ \\
\hline 1990 & 1 & 200 & 1609 & 1809 \\
\hline 1991 & 2 & 400 & 1840 & 2240 \\
\hline 1992 & 7 & 1400 & 1942 & 3342 \\
\hline 1993 & 4 & 800 & 2306 & 3106 \\
\hline 1994 & 11 & 2200 & 2472 & 4672 \\
\hline 1995 & 23 & 4600 & 3126 & 7726 \\
\hline 1996 & 11 & 2200 & 3635 & $5836^{b}$ \\
\hline 1996 & 23 & 4600 & 6264 & $10864(17 / 1000)^{c}$ \\
\hline
\end{tabular}

Source: Ref. 31. (Table 4.2 and Figure 4.4).

Underestimate attributable to reporting delays in death notifications of up to two years.

If we assume that the number of opiate-related deaths in 1996 will be at least the same as those occurring in 1995, and instead of using the number of opiate users identified from treatment we use the number of opiate users identified from the multisource enumeration described above. Using this approach we arrive at a prevalence estimate of 10,864 or $17 / 1000$ opiate users in Dublin in 1996. We shall see in the next section how this result compares favorably with that derived using capture-recapture methods.

\section{Application of the Multivariate Indicator Method to Irish Data}

The Republic of Ireland is divided into 26 counties that are then combined for the provision of health-related services into eight different regions each with its own Health Board. Although there is some information published on a national or city level relating to the five data indicators discussed in the methods section, there is very little stratified data available for each of the Health Board Regions. There are two exceptions to this. One is the Health Research Board National Reports on Treated Drug Misuse, the other is the data on hospital discharges or H1PE database, the data from which we examined at Dublin city level in our section earlier. The HIPE database provides information at county level, which can then be collated into Health Board Region. Table 5 details the national data currently available at Health Board level.

Only two indicators are available at a regional level. In addition, there are only two anchor points available. The Eastern Health Board anchor point refers to Dublin City only and the Southern Health Board anchor point may not be reliable. Because of the considerable, data demands of the method and the limitations in the data available, the method could not be reliably applied to regions within Ireland. 
Table 5. Multiple Indicators and Anchor Points at Regional Level

\begin{tabular}{lllll}
\hline $\begin{array}{l}\text { Variable } \\
\text { Description }\end{array}$ & $\begin{array}{l}\text { AlIn Treatment } \\
1996\end{array}$ & $\begin{array}{l}\text { ElHospital } \\
\text { Discharges } \\
1996\end{array}$ & $\begin{array}{l}\text { F\Population 15- } \\
54\end{array}$ & $\begin{array}{l}\text { G\Ancho } \\
\text { Years } \\
\text { Point }\end{array}$ \\
\hline North Eastern & 0 & 6 & 170071 & \\
Eastern & 3771 & 731 & 775538 & $13460^{\mathrm{a}}$ \\
(Dublin) & $(3635)$ & $(707)$ & $(635329)$ & \\
Midland & 7 & 4 & 112079 & \\
South Eastern & 14 & 6 & 216571 & $1473^{\mathrm{b}}$ \\
Southern & 14 & 10 & 306931 & \\
Mid Western & 27 & 3 & 178029 & \\
Western & 3 & 7 & 189818 & \\
North Western & 1 & 5 & 111991 & \\
All boards & 3837 & 772 & 2061028 & \\
\hline a
\end{tabular}

Estimate based on a capture-recapture study of opiate use in Dublin in 1996, details of which are below.

The author states that 10 of a sample of $2095(0.48 \%)$ of those surveyed admitted recent opiate use. We apply the same percentage use to the total population in the SHB region [Source: Ref. (10)].

In addition, it is obvious from the geographical distribution of the data in Table 5 that the main opiate use is within the Eastern Health Board and in particular within Dublin City.

\section{Application of the Capture-Recapture Method with Three Data Sources and Log- Linear Modeling}

The method was applied using the three data sources obtained for the multisource enumeration study. The first stage of implementation of the method involved removing duplicates from the data and identifying which cases were recorded in two or more samples. This may be done using five types of identification available for each sample: 1) date of birth, 2) sex, 3) forename initial, 4) surname initial, and 5) postal code. Confidentiality can be maintained throughout the entire process and the identification of all persons remains unknown, Cases may be matched using a sort procedure on a standard statistical package such as SPSS/PC or SAS. Once the number of unique individuals within each sample and the overlap between samples have been determined, prevalence estimates may be obtained using the standard formulae and techniques. Finally using the statistical package GLIM, log-linear regression models may be fitted to the data to determine possible dependence between samples. 


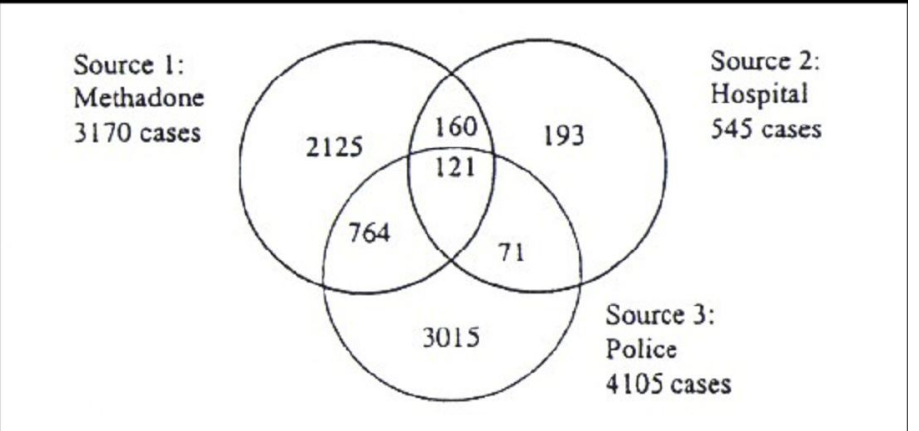

Figure 1. Overlaps between the three data sources.

Prevalence estimates based on the three data sources are provided and the best estimates are derived after a sex and age stratification of the three data sets. Note that in this analysis 134 cases were removed from the police data as these did not have a known Dublin postal code.

Figure 1 illustrates and summarize the overlaps between each source for all age groups. Table 6 provides overlaps for the 15-54 year age range.

Using published methods (22), and the statistical modeling package GLIM together with macros devised by Cormack, Comiskey, and Hay, log-linear models for capturerecapture studies were fitted. This analysis provides reliable prevalence estimates. The details of the best fitting model within each layer of stratification along with an estimate of the model fit and the resulting hidden prevalence estimate are provided in Table 7.

Table 8 provides a detailed summary of the obtained estimates. Included are the known numbers of cases, the estimated hidden population, the overall estimate, and $95 \%$ confidence intervals for these estimates.

\section{DISCUSSION}

It is evident from the raw data prevalence and estimated prevalence in Table 8 that males in the 15-24 age group represent the single largest group of opiate users. Pooling the three raw data sources as we did in our multisource enumeration we see that prevalence in this group is 25 per 1000 of population or, alternatively, it may be stated that a minimum of $2.5 \%$ of all males in this age group are known to be using opiates. Looking at the ratio of known population to hidden population we see that males between 35 and 54 years are the most hidden group. We may interpret this as the group least likely to come into contact with the medical or legal services. Those most likely to come into contact with services, e.g., the most visible or accessible group we see are males between the ages of 25 and 34. With females the same phenomenon is seen within the same age groups. 
Table 6. Data from the Three Samples Illustrating the Overlaps Between Data Sources for Those Aged from 15 to 54 Years

\begin{tabular}{lllll}
\hline & Source 1 Present, & Source 1 Present, & Source 1 Absent, & Source 1 Absent, \\
Source 3 & source 2 Present & Source 2 Absent & Source 2 Present & Source 2 Absent \\
\hline Present & 121 & 764 & 71 & 2831 \\
Absent & 160 & 2124 & 193 & - \\
\hline
\end{tabular}

Table 7. Prevalence Estimates for the Hidden Population of Opiate Drug Users Showing the Best Fitting Model

\begin{tabular}{lllllll}
\hline Group & Best Model & $\mathrm{C}^{2}$ & $\mathrm{df}$ & $\mathrm{p}$ Value & $\mathrm{N}$ & $95 \% \mathrm{Cl}$ \\
\hline Males 15-24 & $+\mathrm{S} 1 \times \mathrm{S} 2$ + S2 x S3 & 0.30 & 1 & .58 & 2935 & $2511-3422$ \\
Males 25-34 & + S1 x S2 & 9.89 & 2 & .01 & 1638 & $1402-1904$ \\
Males 35-54 & + S1 x S2 & 5.31 & 2 & .07 & 893 & $641-1239$ \\
Females 15-24 & + S1 X S2 + S2 x S3 & 6.77 & 1 & .01 & 1023 & $770-1353$ \\
Females 25-34 & + S1 X S2 + S2 x S3 & 1.40 & 1 & .24 & 533 & $369-759$ \\
Females 35-54 & + S1 x S2 & 3.67 & 2 & .12 & 174 & $80-365$
\end{tabular}

S1 = Source 1, methadone; S2 = Source 2, hospital; S3 = Source 3, police.

In the light of prevalence estimates ranging from 6264 from intensive case finding to over 10,864 from the death multiplier method (both methods which are known to provide underestimates) to 13,460 from the capture-recapture method it would seem prudent for planning purposes to assume that in Dublin in 1996 there were at least 11,000 to possibly 14,000 opiate users. Opiate user here is defined in a broad context to cover both "problematic" and "nonproblematic" user. It should also be remembered that the majority of these users are male and within the 15-24 year age bracket. The wider implications of the findings in the present study need to be addressed. For instance we know that $80 \%$ of those drug users tested for Hepatitis C were found to be Hep C seropositive (32). Analysis of the extent and spread of prevalence of Hep C among the hidden group of drug users is essential for planning and provision of medical and social services for those affected.

On a European comparison this estimate is in accordance with estimates published by other European cities. In Barcelona an opiate drug user population prevalence of 9.2/1000 was estimated (33). Estimates of prevalence of injecting drug use in Glasgow were found to be $13.5 / 1000$ with this rising to $43.45 / 1000$ in males aged between 20 and 24 years (34). High prevalence among young males is noted in our study also, as can be seen from Table 7 where a prevalence rate of 56/1000 is estimated for males aged 15-24 years. In a similar study in Setubal, Portugal, prevalence of opiate use among males aged 15-24 years was estimated to be 53/1000 (private communication). Finally, in Dundee, Scotland, the prevalence of opiate use was estimated to be $30 / 1000$ (35).

Please use the following citation: Comiskey C (2001) Methods for estimating prevalence of opiate use as an aid to policy and planning, (Author postprint) in Substance Use \& Misuse, 36(1-2):131-50 [Accessed: (date) from www.drugsandalcohol.ie] 
Table 8. Estimated Prevalence of Opiate Use in Specific Populations in Dublin in 1996

\begin{tabular}{|c|c|c|c|c|c|c|c|}
\hline & $\begin{array}{l}\text { Known } \\
\text { Number }\end{array}$ & $\begin{array}{l}\text { Estimated } \\
\text { Hidden } \\
\text { Number }\end{array}$ & $\begin{array}{l}\text { Ratio of } \\
\text { Known } \\
\text { to } \\
\text { Hidden }\end{array}$ & $\begin{array}{l}\text { Estimated } \\
\text { Total }\end{array}$ & $\begin{array}{l}95 \% \text { C.I. for the } \\
\text { Total Estimate }\end{array}$ & $\begin{array}{l}\text { Known } \\
\text { Prevalence } \\
\text { per } 1000 \\
\text { Population }\end{array}$ & $\begin{array}{l}\text { Estimated } \\
\text { Prevalence } \\
\text { Per } 1000 \\
\text { Population }\end{array}$ \\
\hline Male (15-24) & 2469 & 2935 & $1: 1.19$ & 5404 & $4980-5891$ & 25 & 56 \\
\hline Male $\left(25-34^{a}\right)$ & 1874 & 1638 & $1: 0.87$ & 3512 & $3276-3778$ & 22 & 42 \\
\hline Male (35-54) & 534 & 893 & $1: 1.67$ & 1427 & $1175-1773$ & 4 & 11 \\
\hline Female $\left(15-24{ }^{a}\right)$ & 755 & 1023 & $1: 1.35$ & 1778 & $1525-2108$ & 8 & 18 \\
\hline Female (25-34) & 506 & 533 & $1: 1.05$ & 1039 & $875-1265$ & 6 & 11 \\
\hline Female (35-54) & 126 & 174 & $1: 1.38$ & 300 & $206-491$ & 1 & 2 \\
\hline Total & 6264 & 7196 & $1: 1.15$ & 13460 & $12037-15306$ & 10 & 21 \\
\hline
\end{tabular}

a

Indicates a poor-fitting model and hence not a reliable estimate.

It is both important and interesting to note how results from prevalence estimation techniques vary depending on the methodology used. For Dublin, results varied from 6264 with the multisource enumeration technique to 10,864 based on the mortality multiplier technique to 13,460 using the capture-recap cure methodology. In this first instance we are measuring the number of opiate users who have come into contact with a service, in the second we are measuring what we may call problematic users who have a risk of death, and in the final analysis we are measuring the number of more general opiate users or non-problematic users. This disparity of results clearly demonstrates how important the definition of opiate use within a study is and how the scope of this definition is crucial to the prevalence estimate derived. With any prevalence estimation study, one should first clearly outline the definition of opiate use before one decides on an appropriate method for estimation.

Once the definition is decided upon, then the next consideration is the availability of the necessary data and an analysis of the limitations of the method. While the death multiplier method is easy to understand and apply, data on opiate-related deaths might not be readily available (as was the case with this study, Government ministerial approval for access to the data was required). In addition (again as is the case in Ireland), not all opiate-related deaths may be reported or there may be a considerable time delay in reporting. In addition, with the death multiplier method it is important to choose the multiplier correctly. However, if the data is available, this method does provide a quick and easy approach to a minimum prevalence estimate. If a more comprehensive study is to be undertaken then it is recommended that a multisource enumeration be conducted followed by a capture-recapture study. Again, it is important to clearly outline the definition of opiate use prior to such a study. Finally, it is the opinion of the author that no one study will provide a comprehensive prevalence estimate and that a range of approaches, definitions, and methods need to be applied before one can provide policy planners with a clear picture of the profile, nature, and extent of opiate use.

Please use the following citation: Comiskey C (2001) Methods for estimating prevalence of opiate use as an aid to policy and planning, (Author postprint) in Substance Use \& Misuse, 36(1-2):131-50 [Accessed: (date) from www.drugsandalcohol.ie] 
It was stated at the outset by Reuter (1) that prevalence estimation ought to be a fundamental element of the policy decision-making process. This sentiment is reiterated in Refs. $(36,37)$, in which the authors state that this role is in need of development; in practice, prevalence estimation has not been important enough in policy-making. Instead of providing gross measures to show that a city has a large drug problem what is required are answers to a series of questions the policy maker may pose. The first and perhaps most important of these is "what is the extent of the problem?" Indeed we may ask prior to this, what exactly is the problem and for whom? Who benefits from the problem and who benefits from the solution? Subsequently, policy makers may wish to know who is using drugs, what is the nature of the drug use, the costs incurred because of drug use, and whether the problem is getting better or worse. In this first comprehensive study of prevalence estimation in Ireland it is hoped that some of these questions have been addressed. In addition it is hoped that the discussion of the methods and an illustration of their application will provide assistance and insight for other similar cities worldwide. Finally in the words of N.T.J. Bailey (38):

In the light of suffering on a worldwide scale, epidemic theory is a luxury mankind can ill afford, the world must not only be interpreted it must be changed.

\section{REFERENCES}

1. Reuter, P. Prevalence Estimation and Policy Formation. In Prevalence Estimation. Tehniques for Drug Using Populations, Journal of Drug Issues; Rachin, R.L., Ed.; Spring 1993 (Special issue).

2. European Monitoring Centre for Drugs and Drug Addiction (EMCDDA). National Prevalence Estimates: Improvement of Comparability of National Estimates of Addiction Prevalence, IFT Report on Project CT.96.EP.06 for the EMCDDA; EMCDDA: Lisbon, 1997.

3. EMCDDA. Estimating the Prevalence of Problem Drug Use in Europe; EMCDDA: Lisbon, 1997; 9-13; Scientific Monograph Series, No. 1.

4. EMCDDA. Study of Options to Develop Dynamic Models of Drug Use and Related Problems Using Epidemiological Data, University of York Report on Project CT.96.EP.05 for the EMCDDA; EMCDDA: Lisbon, 1997.

5. WHO. World Health Organisation Programme on Substance Abuse, Linking Dynamic Modelling to Activities, Presentation Made to the EMCDDA Meeting on Dynamic Modelling of Drug Use Problems, Lisbon, May 1998.

6. United Nations Drug Control Programs (UNDCP). World Drug Report; Oxford University Press: Oxford, 1997.

7. Hay, G. Estimating the Prevalence of Substance Misuse. Preprint, Ch. 1. submitted.

8. Comiskey, C.M.; Barry, J. The Prevalence and Health Implications of Opiate Use in Dublin. To appear in European Journal of Public Health (2001).

9. Hartnoll, R. General Introduction: Estimating the Prevalence of Problem Drug Use in Europe; EMCDDA: Lisbon, 1997; 9-13; EMCDDA Scientific Monograph Series, No. 1. 
10. Jackson, T.M.R. Smoking, Alcohol, and Drug Use, Report for the Department of Health, Southern Health Board, Ireland; Department of Health, Southern Health Board: Ireland, 1997.

11. Olsson, B.; Carlsson, G.; Fant, M.; Johanson, T.; Olsson, O.; Roth, C. Heavy Drug Abuse in Sweden 1979-A National Case Finding Study. Alcohol Drug Depend. 1981, 7, 273-283.

12. ESPAD. Alcohol and Drug Use among Students in 26 European Countries, The 1995 ESPAD Report; The Swedish Council for Information on Alcohol and Other Drugs, CAN: Sweden, 1997.

13. Hartnoll, R.; Lewis, R.; Mitcheson, M.; Bryer, S. Estimating the Prevalence of Opiate Dependence. Lancet 1985, 26, 203-205.

14. Dupont, R.L.; Piemme, T.E. Estimation of the Number of Narcotic Addicts in an Urban Area. Med. Ann. DC. 1973, 42 (7), 323-326.

15. Comiskey, C.M. Integral Equations and Estimating the Incidence of HIV Infection. Zeitschrift fur Angewandte Mathematik und Mechanik 1996, 76, 505-506.

16. Comiskey, C.M.; Ruskin, H.J. AIDS in Ireland: The Reporting Delay Distribution and the Implementation of Integral Equation Models. Comput. Appl. Biosci. (CABIOS) 1992, 8, 579-581.

17. Buhringer, G.; Adelsberger, K; Heinemann, A.; Kirschner, J.; Knaub, I.; Krauss, L.; Puschel, K.; Simon, R. SUCHT, Zeitschrift fur Wissenschaft und Praxis; Sucht 1997, 43 (2), S88-S93, S123.

18. Davoli, M; Perucci, C.A.; Forastiere, E; Doyle, P.; Rapid, E.; Zaccarelli, M.; Abeni, D.D. Risk Factors for Overdose Mortality: A Case Control Study within a Cohort of Intravenous Drag Users. Int. J. Epidem. 1993, .'2 (2), 273-277.

19. Mariani, F. The Multivariate Indicator Method. In National Prevalence Estimates. Improvement of Comparability of National Estimates of Addiction Prevalence, IFT Report on Project CT.96.EP.06 for the EMCDDA; EMCDDA: Lisbon, 1997.

20. Mariani, F.; Guaiana, R.; Di Fiandra, T. An Epidemiological Overview of the Situation of Illicit Drag Abuse in Italy. J. Drag Iss. 1994, 24, 579-595.

21. Person, PH.; Retka, R.L.; Woodward, J.A. Toward a Heroin Problem Index-An Analytical Model for Drug Use Indicators, Techincal Paper; US Department of Health Education and Welfare and National Institute on Drug Abuse: Washington, DC, 1976.

22. Bishop, Y.M.M.; Fienberg, S.E.; Holland, P.W. Discrete Multivariate Analysis, Theory and Practice, 12th Edn.; MIT Press: Cambridge, MA, 1995.

23. International Working Group for Disease Monitoring and Forecasting. CaptureRecapture and Multiple-Record Systems Estimation I: History and Theoretical Development. Am. J. Epidemiol. 1995,142 (10), 1047-1058.

24. International Working Group for Disease Monitoring and Forecasting. CaptureRecapture and Multiple-Record Systems Estimation II: Applications in Human Diseases. Am. J. Epidemiol. 1995, 142 (10), 1059-1068.

25. Korf, D.J.; Reijneveld, S.A.; Toet, J. Estimating the Number of Heroin Users: A Review of Methods and Empirical Findings From the Netherlands. Int. J. Addict. 1994,29(11), 1393-1417.

Please use the following citation: Comiskey C (2001) Methods for estimating prevalence of opiate use as an aid to policy and planning, (Author postprint) in Substance Use \& Misuse, 36(1-2):131-50 [Accessed: (date) from www.drugsandalcohol.ie] 
26. Larson, A.; Stevens, A.; Wardlaw, G. Indirect Estimates of 'Hidden 'Populations: Capture-Recapture Methods to Estimate the Numbers of Heroin Users in the Australian Capital Territory. Soc. Set. Med. 1994, 39 (6), 823-831.

27. Abeni, D.D.; Brancato, G.; Perucci, C.A. Capture-Recapture to Estimate the Size of the Population with HIV Type 1 Infection. Epidemiology 1994,5 (4), 410-414.

28. Mastro, T.D.; Kitayaporn, D.; Weniger, B.G.; Vanichseni, S.; Laosunthorn, V.; Uneklabh, T; Uneklabh, C.; Choopanya, K.; Limpakarnjanarat, K. Estimating the Number of HIV-Infected Injection Drug Users in Bangkok: A Capture-Recapture Method. Am. J. Pub. Health 1994, 84 (7), 1094-1110.

29. EMCDDA. Methodological Pilot Study of Local Prevalence Estimates, Report on Project CT.96.EP.07; EMCDDA: Lisbon, 1997.

30. Keogh, E. Illicit Drug Use and Related Criminal Activity in the Dublin Metropolitan Area, Research Report No. 10/97; Garda Research Unit: Dublin, 1997.

31. Moran, R.; O'Brien, M.; Duff, P. Treated Drug Misuse in Ireland, National Report 1996 for the Health Research Board; Health Research Board: Dublin, 1997.

32. Smyth, R.; Keenan, E.; Dorman, A.; O'Connor, J. Hepatitis C Infection among Injection Drug Users Attending the National Drug Treatment Centre. Ir. J. Med. Sci. 1995 (Oct-Dec), 267, 268.

33. Domingo-Salvany, A.; Hartnoll, R.; Maguire, A.; Sueives, J.; Anto, J.M. Use of Capture-Recapture to Estimate the Prevalence of Opiate Addiction in Barcelona, Spain, 1989. Am. J. Epidemiol. 1995, 14 (96), 567-574.

34. Frischer, M. Estimated Prevalence of Injecting Drug Use in Glasgow. Br. J. Addict. 1992, 87, 235-243.

35. Hay, G.; McKeganey, N. Estimating the Prevalence of Drug Misuse in Dundee, Scotland: An Application of Capture-Recapture Methods. J. Epidemiol. Pub. Health 1996, 50 (4), 469-472.

36. Cohen, P. The Relationship between Drug Use Prevalence Estimation and Policy Interests. In Estimating the Prevalence of Problem Drug Use in Europe; EMCDDA: Lisbon, 1997; EMCDDA Scientific Monograph Series, 'No. 1.

37. Stimson, G.V.; Judd, A. Estimating the Scale and Nature of Drug Problems: The Relationship between Science, Policy and Drugs Strategy. In Estimating the Prevalence of Problem Drug Use in Europe; EMCDDA: Lisbon, 1997; 9-13; EMCDDA Scientific Monograph Series, No. 1.

38. Bailey, N.TJ. The Mathematical Theory of Infectious Diseases; Griffin Publishers: London, 1957.

Please use the following citation: Comiskey C (2001) Methods for estimating prevalence of opiate use as an aid to policy and planning, (Author postprint) in Substance Use \& Misuse, 36(1-2):131-50 [Accessed: (date) from www.drugsandalcohol.ie] 